\title{
Pandemi Döneminde ve Pandemi Öncesi Dönemde Acil Servise Başvuran Hastaların Karşılaştırılması
}

\section{Comparison of Patients Admitted to The Emergency Department During and Before the Pandemic Period}

\author{
Ömer Doğan ALATAŞ, Kemal GÖKÇEK
}

Muğla Sttk1 Koçman Üniversitesi Eğitim ve Araştırma Hastanesi, Acil Kliniği, Muğla

\begin{abstract}
Öz
Yeni koronavirüs enfeksiyonu (COVID-19) ilk olarak Çin'in Wuhan kentinde Aralık 2019'da ortaya çıkıp daha sonra tüm dünyaya yayıldı. Çalışmamızda COVID-19 pandemisi sırasında acil servise başvuran hastalıkları belirlemeyi ve bir önceki yıl aynı dönemde başvuran hastalıklarla karşılaştırmayı amaçladık. MartNisan-Mayıs 2019 tarihleri ile Mart-Nisan-Mayıs 2020 tarihlerinde Muğla Sıtkı Koçman Üniversitesi Eğitim ve Araştırma Hastanesi Acil Servise gelen ve yatışı yapılan hastalar calıșmaya alınmıstır. 2019 ve 2020 yılı aynı aylarında acil servise başvuran hasta sayısı 2019 yılında 31534 iken bu sayı 2020 yılında 14323'tür. Hastaları yıllara göre 2 gruba ayırdığımızda; 2020 yılında 2019 yılına göre enfeksiyon hastalıkları servisine, gögüs hastalıkları servisine, kardiyoloji servisine yatış anlamlı artmistır (sirasiyla $\mathrm{p}<0.001, \mathrm{p}=0.012, \mathrm{p}<0.001$ ). 2020 yılında 2019 yılına göre göğüs cerrahi servisine, kadın doğum servisine, kulak burun boğaz servisine, nöroloji servisine, ortopedi servisine, üroloji servisine yatıș anlamlı azalmıștır (sırasıyla $\mathrm{p}<0.001, \mathrm{p}=0.001, \mathrm{p}=0.010, \mathrm{p}<0.001, \mathrm{p}=0.005)$. Sonuç olarak pandemi sırasında Covid-19 yayılmasını önlemek için alınan tedbirler, acil servis başvurularını önemli ölçüde azaltmasına rağmen hastaneye yatış sayısı artmıştır. Özellikle pandemi döneminde akut koroner sendromlu ve stroke ile gelen hasta sayısının artmış olması AKS ve stroke düşünülen hastalarda daha dikkatli olmamızı ve hızlı müdahaleyi gerektirir
\end{abstract}

Anahtar Kelimeler: Acil Servis, Covid-19, Pandemi

\section{Giriş}

Aralık 2019'da ilk olarak Çin'in Wuhan kentinde nedeni bilinmeyen pnömoni vakaları bildirilmiştir. Şiddetli akut solunum sendromu koronavirüs 2 (SARS - CoV - 2) olarak adlandırılan patojen, enfekte hastaların alt solunum yollarından izole edilmiş olup ortaya çıkan hastalık COVID-19 (Coronavirus Disease 2019) olarak adlandırılmıştır (1). SARS - CoV -2 olarak da adlandırılan virüs; pandemik hastalık düzeyine ulaşana kadar Çin ve Dünya genelinde hızla yayılmıştır (1-4). Hastalık 11 Mart 2020 tarihinde Türkiye'ye ulaşmış ve Nisan'da tüm ülkemize yayılmıştır. 16 Mart 2020'den itibaren virüsün yayılmasını önlemek için kısıtlamalar Ömer Doğan ALATAŞ Kemal GÖKÇEK ORCID No 0000-0003-1574-3846 $0000-0002-9295-4965$

Başvuru Tarihi / Received: $\quad$ 10.01.2021 Kabul Tarihi / Accepted : $\quad$ 14.09.2021

Adres / Correspondence : $\quad$ Ömer Doğan ALATAŞ Muğla Sıtkı Koçman Üniversitesi Eğitim ve Araştırma Hastanesi, Acil Kliniği, Muğla e-posta / e-mail alatasomerdogan@gmail.com

\begin{abstract}
The new coronavirus infection (COVID-19) first appeared in Wuhan, China in December 2019 and then spread around the world. In our study, we aimed to determine the diseases that presented to the emergency department during the COVID-19 pandemic and to compare them with the diseases that presented in the same period of the previous year. Patients, who were admitted to the Emergency Department of Muğla Sıtkı Koçman University Training and Research Hospital between March-April-May 2019 and MarchApril-May 2020, were included in the study. While the number of patients admitted to the emergency department in the same months of 2019 and 2020 was 31534 in 2019, this number was 14323 in 2020. When we divide the patients into 2 groups according to years; Admission to the infection service, chest diseases service and cardiology service increased significantly in 2020 compared to 2019 ( $\mathrm{p}<0.001, \mathrm{p}=0.012, \mathrm{p}<0.001$, respectively). Admission to thoracic surgery service, obstetrics service, otolaryngology service, neurology service, orthopedic service, urology service decreased significantly in 2020 compared to 2019 ( $\mathrm{p}<0.001, \mathrm{p}=0.001$, $\mathrm{p}=0.010, \mathrm{p}<0.001, \mathrm{p}=0.005$, respectively). As a result, the measures taken to prevent the spread of Covid-19 during the pandemic significantly reduced emergency department admissions, but increased the number of hospitalizations. The increased number of patients with acute coronary syndrome (ACS) and stroke, especially during the pandemic period, requires us to be more careful and perform rapid intervention in patients with ACS and suspected stroke.
\end{abstract}

Keywords: Emergency Department, Covid-19, Pandemic

çıkarılmaya başlanmıştır. İlk olarak, okullar ve tüm halka açık yerler kapatılmıştır. Kamu hizmetinde çalışanlara esnek mesai uygulaması başlanmış, hastanede poliklinik uygulamalarında da esnek mesaiye geçilmiş ve poliklinik sayısı azaltılmıştır (5). $\mathrm{Bu}$ durum da acil servislerin iş yükünü arttırmıştır.

Biz de çalışmamızda Acil servislerin iş yükünün arttığı COVID-19 pandemisi sirasında acil servise başvuran hastalıkları belirlemeyi ve bir önceki yıl aynı dönemde başvuran hastalarla karşılaştırmayı, hastaların ve hastalıkların genel özelliklerini ortaya koymayı ve literatüre katkı sağlamayı amaçladık.

\section{Gereç ve Yöntem}

Bu tek merkezli retrospektif çalışma 3. Basamak bir acil servis hastanesi olan Muğla Sitkı Koçman Üniversitesi Eğitim ve Araştırma Hastanesinde gerçekleşmiştir. Çalışmaya başlamadan önce üniversitemiz insan araştırmaları etik kurulundan onay alınmıştır (Başvuru No:200262, Tarih:08/12/2020). Çalışmaya erişkin acil servisimize Mart-Nisan-Mayis 2019 tarihleri ile 
Mart-Nisan-Mayıs 2020 tarihlerinde Muğla Sitk1 Koçman Üniversitesi Eğitim ve Araştırma Hastanesi Acil Servise gelen ve yatışı yapılan tüm hastalar dahil edilmiştir. Tüm hastaların verilerine ulaşılmıştır.

Hastanemizin kullandığ 1 Karmed (Kardelen yazılım) yazılım ve işletim sisteminde belirlenen tarihte acil servisimizden servislere yatan hastaların dosyalarına ve yazılım sistemi üzerindeki bilgilerine bakılarak ulaşılmıştır. Hastalar için bir veri formu oluşturulmuş olup veri formunda hastalara ait cinsiyet, yaş, yatış tanıları ve sonraki ex durumları kaydedilmiştir. Her iki yılda da anestezi, dahiliye, kadın doğum, kardiyoloji, ortopedi, göğüs hastalıkları, genel cerrahi, nöroloji, enfeksiyon ve diğer servislere yatan hasta sayıları kaydedilmiştir. Yatan hastaların tanıları akut koroner sendrom (AKS), COVID-19, gebelikle ilgili problemler, kalp yetmezliği, kronik obstruktif akciğer hastalığ1 (KOAH), pnömoni, stroke, böbrek yetmezliği, apandisit, femur fraktürü, gis (gastrointestinal sistem) kanama, ileus, kanser, kolesistit, kolanjit, tibia fraktürü, pankreatit, kot kırığı tanıları kaydedilmiştir.

Elde edilen değişkenler, Statistical Package for Social Sciences 20.0 for Windows (SPSS Inc., Chicago, IL) kullanılarak analiz edilmiştir. Kantitatif değişkenlerin normal dağılımı KolmogorovSmirnov testi kullanılarak kontrol edilmiş, normal dağılıma ait değişkenlere parametrik testler (Student t testi ), dağılımı normal olmayan değişkenlere parametrik olmayan testler (Mann-Whitney U-testi) uygulanmıştır. $\mathrm{P}$ değerinin 0,05 veya daha düşük değerleri istatistiksel olarak anlamlı kabul edilmiştir. Kümülatif sağkalım oranı Kaplan - Meier yöntemi kullanılarak hesaplandı. Hastane içi mortalite ile ilişkili değiş̧kenleri belirlemek için, değişkenler Cox regresyon analizi ile analiz edilmiştir.

\section{Bulgular}

2019 ve 2020 yılı Mart, Nisan, Mayıs aylarında acil servise başvuran toplam hasta sayısının 45857 , 2019 yılında başvuran hasta sayısının 31534, 2020 yılında başvuran hasta sayısının 14323 olduğu tespit edilmiştir. Aynı dönemde hastaneye yatışı yapılan toplam hasta sayıs1 5651 olduğu görülmüştür. $\mathrm{Bu}$ 5651 hastanın tamamı çalışmaya dahil edilmiştir. Hastaların 2401 (\%42.5)'si 2019 yilında, 3250 (\%57.5)'si 2020 yılında yatışı yapıldığ 1 tespit edilmiştir. Tüm hastaların 2663 (\%47.1)'i kadın, 2988 (\%52.9)'unun erkek olduğu görülmüştür. Yaş ortalamasının $57.87 \pm 21.87$ olduğu gözlenmiştir. Hastaların hangi servise yatışı yapıldı̆̆ incelendiğinde 1259 (\%22.3) hastanın Dahiliye servisine, 853 (\%15.1) hastanın Kardiyoloji servisine, 746 (\%13.2) hastanın Kadın hastalıkları ve doğum servisine, $563(\% 10.0)$ hastanın Göğüs Hastalıkları servisine, 460 (\%8.1) hastanın Ortopedi servisine, 407 (\%7.2) hastanın Genel cerrahi servisine, 353 (\%6.2) hastanın Nöroloji servisine, 219 (\%3.9) hastanın Enfeksiyon hastalıkları servisine, 617 (\%10.9) hastanın diğer servislere yatışının yapıldığı izlenmiştir. Hastaların yıllara göre yattığ 1 servisler tablo 1'de verilmiştir. Hastaları yıllara göre 2 gruba ayırdığımızda; 2020 yılında 2019 yılına göre Enfeksiyon hastalıkları servisine, Gögüs hastalıkları servisine, Kardiyoloji servisine yatış istatistiksel olarak anlamlı şekilde artmıştır (sirasiyla $\mathrm{p}<0.001, \mathrm{p}=0.012, \mathrm{p}<0.001$ ). 2020 y1lında 2019 yılına göre Göğüs Cerrahi servisine, Kadın hastalıkları ve doğum servisine, Kulak burun boğaz servisine, Nöroloji servisine, Ortopedi servisine, Üroloji servisine yatış istatistiksel anlamlı şekilde azalmıştır (sırasıyla $\mathrm{p}<0.001, \mathrm{p}=0.001, \mathrm{p}=0.010$, $\mathrm{p}=0.000, \mathrm{p}=0.005)$ (Tablo 1).

Hastaların tanılarının yıllara göre değerlendirdiğimizde 2020 yılında 2019 yılına göre AKS, covid-19, gebelikle ilgili problemler, pnömoni, kolanjit tanılarıyla hastaneye yatış istatistiksel olarak anlamlı şekilde artmıştır $(p=0.001)$. Kalp yetmezliği, stroke, böbrek yetmezliği, gis kanaması, ileus, kanser, pankreatit tanılarıyla hastaneye yatış ise artmış olup istatistiksel açıdan anlamlılık saptanmamıştır (sirasiyla $\mathrm{p}=0.799, \mathrm{p}=0.190, \mathrm{p}=0.451, \mathrm{p}=0.804$, $\mathrm{p}=0.682, \mathrm{p}=0.192, \mathrm{p}=0.943)$. KOAH, apandisit, femur fraktürü, kolesistit, tibia fraktürü, kot kırığ tanılarıyla hastaneye yatış istatistiksel olarak anlamlı şekilde azalmıştır ( $\mathrm{p}=0.001)$ (Tablo 2).

Hastalara cox regresyon analizi yaparak mortaliteyi etkileyen faktörler araştırıldığında yatış gün sayısı, yoğun bakım ünitesi yatış öyküsü, kardiyoloji servisine yatış öyküsü ve nöroloji servisine yatış öyküsü, AKS tanısına sahip olması ve Stroke tanısının konmasının mortalitenin ön görücüleri olduğu tespit edilmiştir (sırasıyla $\mathrm{p}<0.001, \mathrm{p}<0.001, \mathrm{p}=0.040, \mathrm{p}=0.011, \mathrm{p}<0.001$, $\mathrm{p}=0.020$ ) (Tablo 3, Şekil 1 ve 2).

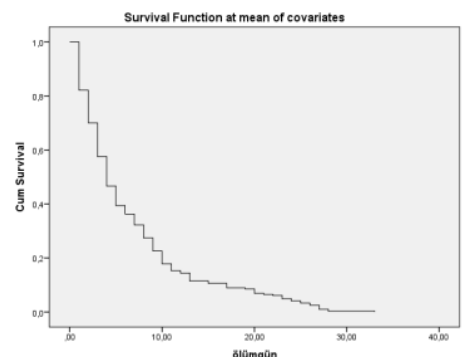

Şekil 1. Kaplan- Meier hayatta kalma eğrisi, yoğun bakımda yatış durumuna göre

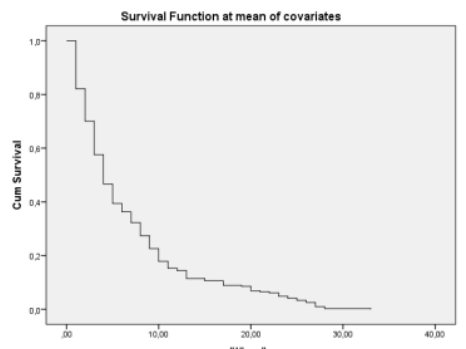

Şekil 2. Cox regresyon analizindemde Hazard eğrisi, yoğun bakım yatış durumuna göre 
Tablo 1. Y1llara göre servislere yatan hasta sayıları

\begin{tabular}{|c|c|c|c|c|}
\hline & $\begin{array}{l}2019 \text { yılında yatış } \\
\text { yapılan hastalar } \\
\text { n }(\%) \\
\end{array}$ & $\begin{array}{l}2020 \quad \text { yılında yatışı } \\
\text { yapılan hastalar } \\
\text { n }(\%)\end{array}$ & $\begin{array}{l}\text { Total yatan hasta } \\
\text { sayısı } \\
\text { n }(\%) \\
\end{array}$ & $\mathbf{p}$ \\
\hline Anestezi & $52(2.2)$ & $122(3.8)$ & $174(3.1)$ & $.431^{\mathrm{x}}$ \\
\hline Dahiliye & $511(21.3)$ & $748(23.0)$ & $1259(22.3)$ & $.122^{\mathrm{x}}$ \\
\hline Kadın doğum & $372(15.5)$ & $374(11.5)$ & $746(13.2)$ & $.000^{x}$ \\
\hline Kardiyoloji & $281(11.7)$ & $572(17.6)$ & $853(15.1)$ & $.000^{\mathrm{x}}$ \\
\hline Ortopedi & $252(10.5)$ & $208(6.4)$ & $460(8.1)$ & $.010^{x x}$ \\
\hline Göğüs hastalıkları & $211(8.8)$ & $352(10.8)$ & $563(10.0)$ & $.012^{\mathrm{x}}$ \\
\hline Genel cerrahi & $207(8.6)$ & $200(6.1)$ & $407(7.2)$ & $.000^{\mathrm{xx}}$ \\
\hline Nöroloji & $173(7.2)$ & $180(5.5)$ & $353(6.2)$ & $.010^{\mathrm{xx}}$ \\
\hline Enfeksiyon & $42(1.7)$ & $177(5.4)$ & $219(3.9)$ & $.000^{\mathrm{x}}$ \\
\hline Diğer servisler & $394(12.5)$ & $223(6.8)$ & $617(10.9)$ & $.000^{x}$ \\
\hline Total & $2401(100)$ & $3250(100)$ & $5651(100)$ & \\
\hline
\end{tabular}

Tablo 2. Y1llara göre hastalık tanıları

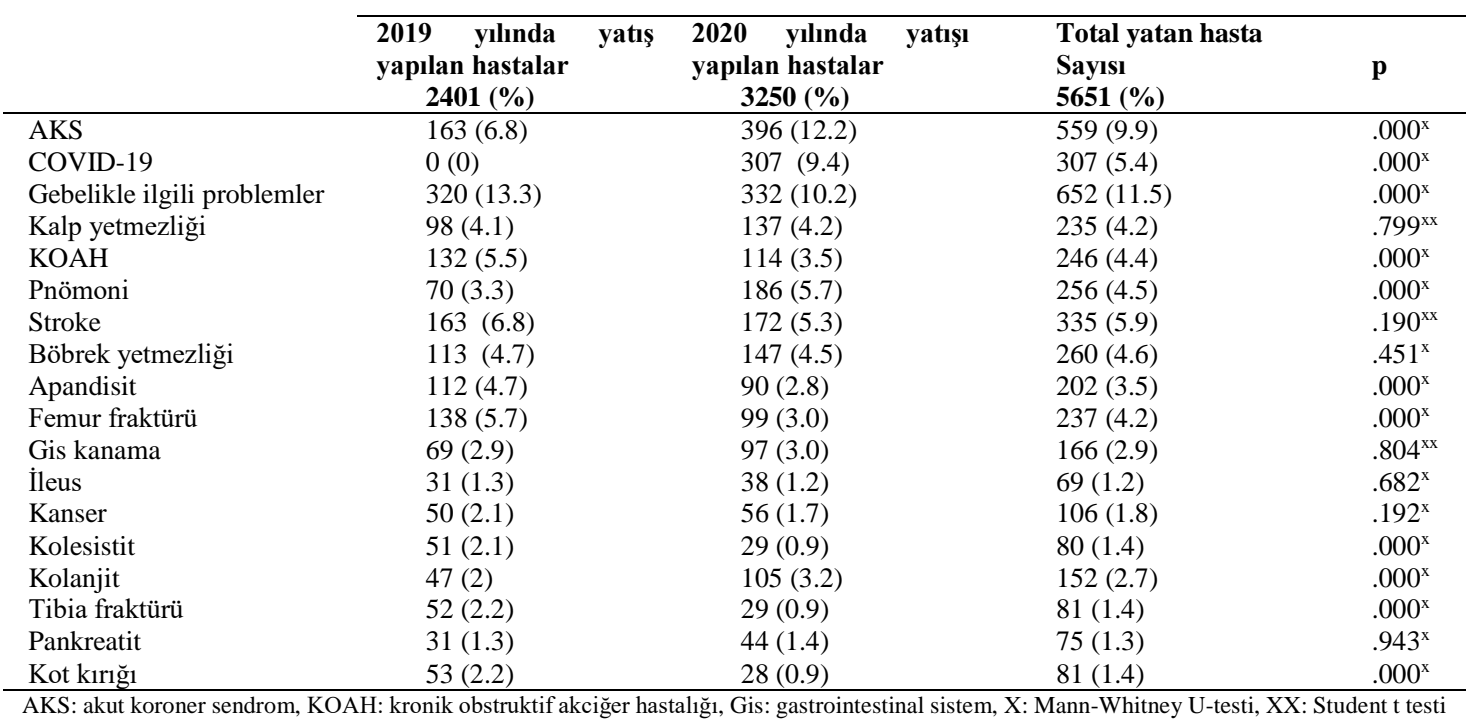

Tablo 3. Mortalite tahmini için cox regresyon analizi

\begin{tabular}{lccc}
\hline 28 gün için değişkenler & Odds ratio & $\mathbf{9 5 \%}$ CI & p \\
\hline Yatış gün sayıs1 & .456 & $.398-.521$ & .000 \\
YBÜ yatış öyküsü & 6.477 & $2.872-14.607$ & .000 \\
Kardiyoloji servisine yatış öyküsü & .614 & $.440-.856$ & .040 \\
Nöroloji servisine yatış öyküsü & 1.952 & $1.164-3.272$ & .011 \\
AKS tanısı & .418 & $.259-.675$ & .000 \\
Stroke tanısı & 1.758 & $1.091-2.831$ & .020 \\
\hline YBÜ: yoğın bakım ünitesi, AKS: akut koroner sendrom & & &
\end{tabular}

YBÜ: yoğun bakım ünitesi, AKS: akut koroner sendrom

\section{Tartışma}

Covid-19 tüm dünyayı etkilemiş ancak en ciddi etkileri sağlık sistemleri üzerine olmuştur. Hastaların bu dönemde hastane başvuru sayısı ve sıklığı değişmekle kalmamış, hastanelere hasta yatışları ve organizasyonları da değișime uğramıștır. Çalışmamızda Covid-19 pandemi döneminde acile başvuran hasta sayısında azalma olmasına rağmen hastaneye yatış oranında bir önceki döneme göre artış izlenmiștir. İkibin yirmi yılında Covid 19 ve Covid 19 ile ilişkili olabilecek hasta yatışlarında artış olmakla birlikte ilginç olarak AKS tanısıyla hasta yatışında da artış olmuştur $(6,7)$. AKS ve stroke morbidite ve mortalitesi yüksek olan, yaygın yaşamı tehdit eden durumlardandır (6). Çalışmamızda
AKS'lu hastalarda pandemi döneminde anlamlı artış saptanmıştır. Diğer çalışmalarda, COVID-19 salgını sırasında MI nedeniyle hastaneye başvurularda önemli düşüşler bildirilmiştir (6-11). Örneğin, Amerika Birleşik Devletleri'nde (ABD) kardiyak kateterizasyon laboratuarında yapılan bir çalışmada, salgından önceki 14 ay ile karşılaştırıldığında mart ayında kalp krizi riskinde \%38'lik bir azalma bulunmuştur (6). California, Massachusetts ve New York City'deki büyük hastane sistemleri, pandemi sırasında MI ve diğer akut kardiyovasküler rahatsızlıklara başvurularda \%43-\%50 azalma bildirmiştir (7-9). Çalışmamızı stroke açısından değerlendirdiğimiz zaman pandemi döneminde stroke sayısı artmış olup anlamlı değildir. ABD'de 850 hastaneden alınan görüntüleme verilerinin 
incelendiği çalışmada, inme belirtileri açısından değerlendirilen hastaların sayısında \%39'luk bir azalma olduğunu ifade edilmiştir (11). Lange ve arkadaşlarının (12) yaptığı bir çalışmada erken pandemi döneminde hem MI'lı hastalarda hem de inmeli hastalarda bizim çalışmamızdan farklı olarak azalma saptanmıştır. Covid-19, çoklu organ disfonksiyonu, sepsis ve yaygın intravasküler tromboz ile karakterize edilebilen ciddi bir klinik tabloya yol açabilir. Bu nedenle, etkilenen hastalar akut koroner sendromlar ve akut serebrovasküler hastalıklar açısından yüksek risk altındadır. Bundan dolayı çalışmamızda akut koroner sendromlu ve inmeli hasta sayısının arttığını düşünmekteyiz.

Çalışmamızda kot fraktürü, femur fraktürü ve tibia fraktürü gibi travma nedeniyle oluşan hastalıklara bağlı yatış oranları pandemi döneminde azalmıştır. Çalışmamızla benzer şekilde Türkiye'de yapılan bir çalışmada da pandemi döneminde travmalı hasta sayısında azalma saptanmıştır (13). Pandemi döneminde sokağa çıkma kısıtlanmasının olması, hastaların hareketli bir yaşamdan daha çok evde kaldığı yaşama zorlamıştır, bu yüzden insanların evde kalması ve toplu mekânlara çıkamamasının travmatik yaralanmaları azaltmış olabileceğini düşünmekteyiz.

Çalışmamızda pandemi döneminde acile gelen covid-19, pnömoni ve enfeksiyon vakalarında artış saptanmıştır. Bu da covid-19'a bağlı olarak pnömoni ve enfeksiyonda artışa neden olduğunu düşünmekteyiz. Yine pandemi döneminde göğüs hastalıkları servisine ve enfeksiyon hastalıkları servisine yatan hasta sayılarındaki artışı da covid 19 artışına bağlamaktayız.

Çalışmamızda pandemi döneminde apandisit ve kolesistit tanılı hastalarda azalmayla birlikte genel cerrahi servisine yatan hasta sayıs da azalma saptanmıştır. Bunu nedenini hastaların enfeksiyon kapma endişesi nedeniyle hastanelere gitmekten kaçındığına bağlamaktayız.

Çalışmamızda pandemi döneminde özellikle Enfeksiyon hastalıkları servisine, Gögüs hastalıkları servisine, Kardiyoloji servisine yatış oranında anlamlı artış saptanmıştır. Literatüre baktığımızda pandemi döneminde servislere yatışı gösteren herhangi bir çalışma bulunmamaktadır. Özellikle literatüre baktığımızda koroner arter hastalığ1 riskinin artmış olması çalışmamızla benzer şekilde kardiyolojiye yatış oranını arttırdığını düşündürmektedir.

Sonuç olarak çalışmamızda pandemi sırasında Covid -19 yayılmasını önlemek için alınan tedbirler, acil servis başvurularını önemli ölçüde azaltmasına rağmen hastaneye yatış sayısı artmıştır.

Etik Kurul Onayı: Muğla Sitkı Koçman Üniversitesi Sağlık Bilimleri Etik Kurulu'ndan onay alınmıştır (Başvuru No:200262, Tarih:08/12/2020).

\section{Kaynaklar}

1. Jin YH, Cai L, Cheng ZS, et al. A rapid advice guideline for the diagnosis and treatment of 2019 novel coronavirus (2019$\mathrm{nCoV}$ ) infected pneumonia (standard version). Mil Med Res. 2020; 7: 4

2. Ng OT, Marimuthu K, Chia PY, et al. SARS-CoV-2 infection among travelers returning from Wuhan, China. N Engl J Med. 2020; 382: 1476-8

3. Phelan AL, Katz R, Gostin LO. The novel coronavirus originating in Wuhan, China: challenges for Global Health governance. JAMA. 2020; 323: 709 .

4. Li Q, Guan X, Wu P, et al. Early transmission dynamics in Wuhan, China, of novel coronavirus-infected pneumonia. N Engl J Med. 2020; 382: 1199-207.

5. https://en.wikipedia.org/wiki/COVID19_pandemic_in_Turkey

6. Garcia S, Albaghdadi MS, Meraj PM, et al. Reduction in STsegment elevation cardiac catheterization laboratory activations in the United States during COVID-19 pandemic. J Am Coll Cardiol. 2020;75:2871-2.

7. Solomon MD, McNulty EJ, Rana JS, et al. The COVID-19 pandemic and the incidence of acute myocardial infarction [Epub May 19, 2020]. N Eng J Med. 2020; 383:691-3.

8. Bhatt AS, Moscone A, McElrath EE, et al. Declines in hospitalizations for acute cardiovascular conditions during the COVID-19 pandemic: a multicenter tertiary care experience. J Am Coll Cardiol. 2020;20:35393-6.

9. Gogia S, Newton-Dame R, Boudourakis L, et al. COVID-19 X-curves: illness hidden, illness deferred [Epub May 29, 2020]. N Eng J Med Catalyst. 2020.

10. Metzler B, Siostrzonek P, Binder RK, et al. Decline of acute coronary syndrome admissions in Austria since the outbreak of COVID-19: the pandemic response causes cardiac collateral damage. Eur Heart J. 2020;41:1852-3.

11. Kansagra AP, Goyal MS, Hamilton S, et al. Collateral effect of COVID-19 on stroke evaluation in the United States [Epub May 8, 2020]. N Eng J Med. 2020;383(4):400-1.

12. Lange SJ, Ritchey MD, Goodman AB, et al. Potential indirect effects of the COVID-19 pandemic on use of emergency departments for acute life-threatening conditions-United States, January-May. Am J Transplant. 2020;69(25):795800 .

13. Görmeli Kurt N, Güneş C. How Has Covid-19 Pandemic Affected Crowded Emergency Services? Int J Clin Pract. 2020 Dec;74(12):e13624. 